\title{
Early Hepatocellular Carcinoma: Definition and Diagnosis
}

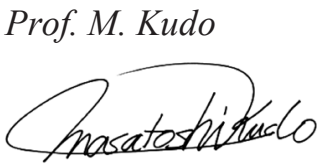

Editor Liver Cancer

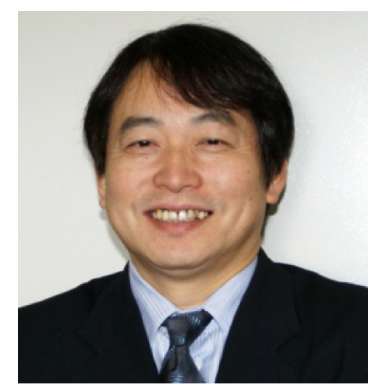

Early hepatocellular carcinoma (HCC) can be described as "early" according to its pathological characteristics as well as its clinical characteristics. Taking the pathological approach first, the term "early" implies that a lesion is at a relatively early stage of carcinogenesis and prognosis is still good. Well-differentiated HCC is not necessarily early HCC. According to the clinical approach, the term "early" is used to differentiate HCC diagnosed in its early developmental stage from that diagnosed at more advanced stages. The clinical approach to diagnosing early HCC is used preferentially in the United States and Europe and, in general, this conceptualization of early HCC refers to tumors smaller than $3 \mathrm{~cm}$ and three or fewer in number at stage A (early stage) with respect to Barcelona Clinic Liver Cancer staging, although it sometimes includes solitary tumors up to $5 \mathrm{~cm}$ in size, as defined in the Milan criteria. Both very early and early stage tumors are relatively small, but both are hypervascular in the arterial phase and are regarded as classic HCC.

The pathological approach, however, defines early HCC as HCC in the early stage of carcinogenesis (generally $\leq 2 \mathrm{~cm}$ ) that is often hypovascular with irregular boundaries on diagnostic imaging and contains portal elements without significantly affecting the original structure of the liver. The pathological characteristics of HCC include its multistep progression from a low-grade to a high-grade dysplastic nodule, to early HCC, and eventually to classic hypervascular HCC [1](fig.1). Accordingly, the accurate diagnosis and proper treatment of early HCC, a precursor of classic (typical) HCC, is extremely important. Therefore, I will discuss here the pathological aspects of early HCC.

According to the General Rules for the Clinical and Pathological Study of Primary Liver Cancer developed by the Liver Cancer Study Group of Japan [2], early HCC is defined as follows. Early HCC exhibits focal structural abnormalities such as acinar or pseudoglandular structures, broken or irregular trabecular alignment, and/or obvious invasion of the stromal tissue. Cellular atypia is usually unremarkable, but the nuclear-cytoplasmic ratio is increased due to decreased amounts of cytoplasm. The cytoplasm also shows eosinophilia or basophilia. The cell density may be more than twice that of the surrounding non-cancerous liver tissue. In addition, lesions often exhibit fatty changes or clear cell changes. Because the cancer cells of early HCCs do not grow expansively, they instead proliferate by replacing ad- 


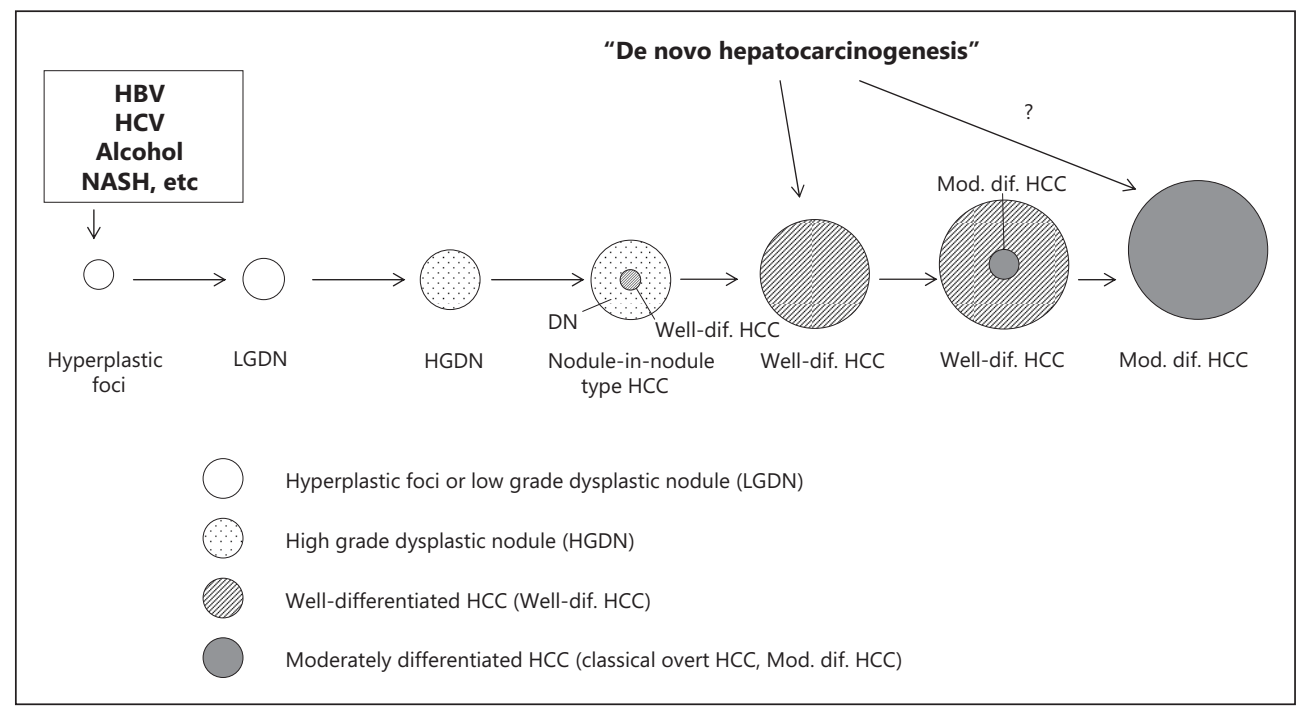

Fig. 1. Schematic representation of multistep progression of human hepatocarcinogenesis. HBV= hepatitis B virus; $\mathrm{HCV}=$ hepatitis $\mathrm{C}$ virus; $\mathrm{NASH}=$ nonalcoholic steatohe patitis.

jacent hepatocytes in a trabecular arrangement at the boundary with surrounding liver tissues, resulting in a poorly demarcated margin. Macroscopically, the lesions are classified as small nodules with indistinct margins [3]. These criteria for early HCC have already gained international consensus [4] and have been incorporated into the World Health Organization's latest "blue book" on digestive system tumors [5]. In addition, several molecular markers for the pathological diagnosis of early HCC have been identified, including heat-shock protein 70 (HSP70) [6], glypican-3 (GPC3) [7], glutamine synthetase (GS), cyclase-associated protein 2, and Bmi-1. Using HSP70, GPC3, and GS markers in combination, the sensitivity and specificity of early HCC diagnosis can be as high as 72 and $100 \%$, respectively [8].

However, accurate differentiation of early HCC from dysplastic nodules is possible only when stromal invasion is found in resected specimens. In other words, differential diagnosis between early HCC and dysplastic nodules is often not possible without the findings of stromal invasion on biopsy. Differentiating between these two types of lesions with imaging used to be challenging, even when using computed tomography (CT) during hepatic arteriography/CT during arterial portography (CTHA/CTAP).

However, the subsequent introduction of gadolinium (Gd)-ethoxybenzyl (EOB)-diethylenetriamine pentaacetic acid (DTPA)-enhanced magnetic resonance imaging (Gd-EOB MRI) has proven to be a major breakthrough in the diagnosis of early HCC. Gd-EOB-DTPA is endocytosed into liver cells via organic anion transporter $8[9,10]$. Because early HCC appears on Gd-EOB MRI images as a hypointense nodular lesion and a dysplastic nodule appears as an iso- or hyperintense lesion on the hepatobiliary phase, the diagnostic accuracy of early HCC is now generally $\geq 95 \%$ [11-13]. Moreover, previous studies have followed up the natural course of hypovascular nodules with hypointense signals on the Gd-EOB MRI hepatobiliary phase and reported that, even if early HCC is ruled out on biopsy, there is a high probability that this type of hypovascular nodule will undergo hypervascular change and transform into typical HCC [14-16]. In other words, even if biopsy excludes early HCC, hypovascular nodules that are hypointense on the Gd-EOB MRI hepatobiliary phase may be regarded as early HCC. At any rate, such lesions can be considered as nodular lesions with a high potential to transform to HCC. 
Reflecting this clinical background, the HCC clinical practice guidelines used in Japan [17] already include a specific algorithm for the diagnosis and treatment of early HCC, whereas the HCC clinical practice guidelines used in the United States and Europe (AASLD and EASLEORTC guidelines $[18,19])$, as well as those in other Asian countries [20], do not contain criteria for the diagnosis and treatment of early HCC. This is a clear indication that, compared with other countries, HCC screening and diagnostic skills are well advanced in Japan, owing in large part to the sophisticated nationwide surveillance system for HCC [21]. Developing measures to identify hypervascular HCCs while they are still curable is currently the biggest challenge facing the United States, Europe, and other Asian countries, where effective nationwide surveillance systems for HCC have not been established. In contrast, the current focus in Japan, where small hypervascular HCCs are routinely diagnosed, is to differentiate early HCC correctly from dysplastic nodules and to develop effective treatment for early HCC defined in accordance with its pathological conceptualization. It is not an overstatement to say that the large gap between Japan's HCC screening/diagnostic capabilities and those of other countries manifests as a large difference in awareness and management of early HCC.

In conclusion, we sincerely hope that other countries will follow the Japanese approach and develop effective nationwide surveillance systems for HCC and join us in constructive dialog aimed at improving the diagnosis and treatment of early HCC.

\section{References}

1 Kudo M: Multistep human hepatocarcinogenesis: correlation of imaging with pathology. J Gastroenterol 2009;44(Suppl 19):112-118.

2 Liver Cancer Study Group of Japan: General rules for the clinical and pathological study of primary liver cancer, 3rd English edition. Kanehara \& Co., Ltd. Tokyo, 2010.

-3 Sakamoto M, Hirohashi S, Shimosato Y: Early stages of multistep hepatocarcinogenesis: adenomatous hyperplasia and early hepatocellular carcinoma. Hum Pathol 1991;22:172-178.

4 Kojiro M, Wanless I, Alves V, et al: Pathologic diagnosis of early hepatocellular carcinoma: a report of the international consensus group for hepatocellular neoplasia. Hepatology 2009;49:658-664.

5 Theise ND, Park YN, Curado MP, Sakamoto M, Franceschi S, Torbenson M, Hytiroglou P, Wee A, Kudo M: Hepatocellular carcinoma. WHO Classification of tumours of the Digestive System, 4th Edition, International Agency for Research on Cancer, Lyon. 2010:205-216.

-6 Chuma M, Sakamoto M, Yamazaki K, Ohta T, Ohki M, Asaka M, Hirohashi S: Expression profiling in multistage hepatocarcinogenesis: identification of HSP70 as a molecular marker of early hepatocellular carcinoma. Hepatology 2003;37:198-207.

7 Libbrecht L, Severi T, Cassiman D, Vander Borght S, Pirenne J, Nevens F, Verslype C, van Pelt J, Roskams T: Glypican-3 expression distinguishes small hepatocellular carcinomas from cirrhosis, dysplastic nodules, and focal nodular hyperplasia-like nodules. Am J Surg Pathol 2006;30:1405-1411.

8 Di Tommaso L, Franchi G, Park YN, Fiamengo B, Destro A, Morenghi E, Montorsi M, Torzilli G, Tommasini M, Terracciano L, Tornillo L, Vecchione R, Roncalli M: Diagnostic value of HSP70, glypican 3, and glutamine synthetase in hepatocellular nodules in cirrhosis. Hepatology 2007;45:725-734.

-9 Narita M, Hatano E, Arizono S, Miyagawa-Hayashino A, Isoda H, Kitamura K, Taura K, Yasuchika K, Nitta T, Ikai I, Uemoto S: Expression of OATP1B3 determines uptake of Gd-EOB-DTPA in hepatocellular carcinoma. J Gastroenterol 2009;44:793-798.

$>10$ Kitao A, Zen Y, Matsui O, Gabata T, Kobayashi S, Koda W, Kozaka K, Yoneda N, Yamashita T, Kaneko S, Nakanuma Y: Hepatocellular carcinoma: signal intensity at gadoxetic acid-enhanced MR Imaging-correlation with molecular transporters and histopathologic features. Radiology 2010;256:817-826.

11 Sano K, Ichikawa T, Motosugi U, Sou H, Muhi AM, Matsuda M, Nakano M, Sakamoto M, Nakazawa T, Asakawa M, Fujii H, Kitamura T, Enomoto N, Araki T: Imaging study of early hepatocellular carcinoma: usefulness of gadoxetic acid-enhanced MR imaging. Radiology 2011;261:834-844.

12 Kudo M: The 2008 Okuda lecture: Management of hepatocellular carcinoma: From surveillance to molecular targeted therapy. J Gastroenterol Hepatol 2010;25:439-452.

13 Kitao A, Matsui O, Yoneda N, Kozaka K, Shinmura R, Koda W, Kobayashi S, Gabata T, Zen Y, Yamashita T, Kaneko S, Nakanuma Y: The uptake transporter OATP8 expression decreases during multistep hepatocarcinogenesis: correlation with gadoxetic acid enhanced MR imaging. Eur Radiol 2011;21:2056-2066.

14 Motosugi U, Ichikawa T, Sano K, Sou H, Onohara K, Muhi A, Amemiya F, Enomoto N, Matsuda M, Fujii H, Araki T: Outcome of hypovascular hepatic nodules revealing no gadoxetic acid uptake in patients with chronic liver disease. J Magn Reson Imaging 2011;34:88-94. 
15 Kumada T, Toyoda H, Tada T, Sone Y, Fujimori M, Ogawa S, Ishikawa T: Evolution of hypointense hepatocellular nodules observed only in the hepatobiliary phase of gadoxetate disodium-enhanced MRI. AJR Am J Roentgenol 2011;197:58-63.

16 Kobayashi S, Matsui O, Gabata T, Koda W, Minami T, Ryu Y, Kawai K, Kozaka K: Gadolinium ethoxybenzyl diethylenetriamine pentaacetic acid-enhanced magnetic resonance imaging findings of borderline lesions at high risk for progression to hypervascular classic hepatocellular carcinoma. J Comput Assist Tomogr 2011;35:181-186.

17 Kudo M, Izumi N, Kokudo N, Matsui O, Sakamoto M, Nakashima O, Kojiro M, Makuuchi M: Management of hepatocellular carcinoma in Japan: Consensus-Based Clinical Practice Guidelines proposed by the Japan Society of Hepatology (JSH) 2010 updated version. Dig Dis 2011;29:339-364.

18 Bruix J, Sherman M: Management of hepatocellular carcinoma: An update. Hepatology 2011;53:10201022.

19 Llovet JM, Ducreux M, et al: EASL-EORTC clinical practice guidelines: management of hepatocellular carcinoma. J Hepatol 2012;56:908-943.

20 Omata M, Lesmana LA, Tateishi R, Chen PJ, Lin SM, Yoshida H, Kudo M, Lee JM, Choi BI, Poon RT, Shiina S, Cheng AL, Jia JD, Obi S, Han KH, Jafri W, Chow P, Lim SG, Chawla YK, Budihusodo U, Gani RA, Lesmana CR, Putranto TA, Liaw YF, Sarin SK: Asian Pacific Association for the Study of the Liver consensus recommendations on hepatocellular carcinoma. Hepatol Int 2010;4:439-474.

21 Kudo M: Japan's successful model of nationwide hepatocellular carcinoma surveillance highlighting the urgent need for global surveillance. Liver Cancer 2012;1:141-143. 